\section{Response to: 'Could autologous adipose-derived stromal vascular fraction turn out an unwanted source of profibrotic myofibroblasts in systemic sclerosis?' by Manetti}

We would like to thank Dr Manetti for his relevant comments ${ }^{1}$ on our recent article in the Annals of Rheumatic Disease entitled 'Molecular profile and proangiogenic activity of the adipose-derived stromal vascular fraction used as an autologous innovative medicinal product in patients with systemic sclerosis' ${ }^{2}$. We are pleased that this study has raised such a high interest in the scientific community and allows us to provide additional comments to those recently published ${ }^{34}$ in order to discuss the potential profibrotic profile of adipose-derived stem cells (ADSC) derived from patients with diffuse cutaneous systemic sclerosis $(\mathrm{SSc})$. We agree that $\mathrm{SSc}$ is a rare but potentially lethal autoimmune disease that challenges the urgent need to develop novel therapeutic approaches. In this context, autologous fat grafting has been successfully used to limit SScassociated clinical complications such as SSc-related perioral thickening and mouth opening limitation ${ }^{5}$ facial handicap ${ }^{6}$ or digital ulcers. ${ }^{7}$ These clinical results opened up research perspectives on autologous adipose tissue based therapies for patients suffering from SSc. However, we agree that the question raised by Dr Manetti : 'Could autologous adipose-derived stromal vascular fraction turn out an unwanted source of profibrotic myofibroblasts in systemic sclerosis?' is of a major concern.

Indeed, some studies performed on skin biopsies in patients with SSc suggested that perivascular cells from the mesenchymal lineage were prone to myofibroblastic differentiation. ${ }^{8}$ However, recent investigations regarding the impact of SSc disease on the disorganisation of the adipose tissue architecture $^{9}$ or altered differentiation capabilities ${ }^{9}$ and reduced proliferation rate and metabolic activity of $\mathrm{ADSC}^{10}$ remain controversial. Conversely, Capelli and colleagues showed that ADSC obtained from patients with SSc exhibit phenotypic pattern, proliferation, immunosuppressive properties and differentiation potential that are similar to the ones observed in healthy controls, emphasising the safety of using autologous ADSC grafting as a therapeutic option for SSc. ${ }^{11}$ The discordance between these studies may be explained by (1) the variable sources and expansion protocols that allow to derive ADSC and (2) the high interindividual heterogeneity between patients with SSc in terms of severity, duration and manifestations of the disease and ongoing treatment. Moreover, these preliminary studies have concerned investigation at the cellular levels whereas it is now well established that the mechanisms sustaining the function of ADSC mainly rely on the secretion of factors able to regulate endogenous cell activity. Although ADSC is one of the most represented cell subtype in adipose-derived stromal vascular fraction (ADSVF), we believe that conclusions driven from ADSC derived in culture from patients with SSc cannot be extrapolated to the freshly isolated autologous therapeutic ADSVF characterised in our study. In line with this assumption, recent studies have highlighted differences in the paracrine content of expanded and non-expanded ADSC and suggest that ADSVF may secrete a larger panel of soluble factors with beneficial properties for cell therapy than ADSC. ${ }^{12}$

Furthermore, although pathogenesis of SSc is not fully understood, it is now recognised that endothelial dysfunction constitutes the primum movens for fibrosis progression. Thus, the SCLERADEC phase I clinical trial (NCT :01813279) and the preserved proangiogenic activity of SSc-ADSVF described in our study suggest that the presence of regenerative endothelial progenitors cells in ADSVF is a major advantage in preventing and/or limiting SScassociated vasculopathy. ${ }^{213}$ In addition, transcriptomic and molecular signatures of SSc are not strictly correlated to the in vivo properties of progenitor cells. Indeed, we have found several markers of endothelial activation and dysregulation in the secretome of ADSVF from patients with SSc, without compromising its vascular repair capacity compared with ADSVF from healthy donors.

Nonetheless, we agree with Dr Manetti that implementation of in vitro and/or in vivo potency assays addressing both vascular and fibrotic properties of ADSVF are needed to define the optimal cellular-based strategies in SSc. From our point of view, such developments can benefit from investigations conducted using a pharmaceutical grade cell therapy product infused in the frame of a controlled clinical trial in order to integrate not only the patients and disease characteristics but also the possible impact of the manufacturing process.

\section{Melanie Velier, ${ }^{1,2}$ Jeremy Magalon $\odot{ }^{1,2}$ Stephanie Simoncini, ${ }^{2}$ Françoise Dignat-George, ${ }^{2}$ Brigitte Granel, ${ }^{2,3}$ Pascale Paul, ${ }^{1,2}$ Florence Sabatier ${ }^{1,2}$ \\ ${ }^{1}$ Cell Therapy Department, Hopital de la Conception, Marseille, France ${ }^{2}$ Cardiovascular and Nutrition Research Center, INSERM, INRA, Aix-Marseille Universite, Marseille, France \\ ${ }^{3}$ Internal Medicine Department, Hopital Nord, Marseille, France}

Correspondence to Professor Florence Sabatier, Marseille, France; florence.sabatier@ap-hm.fr

Handling editor Josef S Smolen

Contributors Drafting of the manuscript: JM, MV, SS. Critical revision of the manuscript for important intellectual content: FD-G, BG, PP and FS.

Funding The authors have not declared a specific grant for this research from any funding agency in the public, commercial or not-for-profit sectors.

Competing interests None declared.

Patient consent for publication Not required.

Provenance and peer review Commissioned; internally peer reviewed.

(c) Author(s) (or their employer(s)) 2020. No commercial re-use. See rights and permissions. Published by BMJ.

\section{Check for updates}

To cite Velier M, Magalon J, Simoncini S, et al. Ann Rheum Dis 2020;79:e56.

Received 18 March 2019

Accepted 18 March 2019

Published Online First 9 April 2019

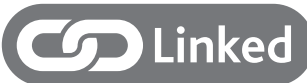

- http://dx.doi.org/10.1136/annrheumdis-2019-215288

Ann Rheum Dis 2020;79:e56. doi:10.1136/annrheumdis-2019-215327

ORCID iD

Jeremy Magalon http://orcid.org/0000-0003-1494-7011

\section{REFERENCES}

1 Manetti Met al. Could autologous adipose-derived stromal vascular fraction turn out an unwanted source of profibrotic myofibroblasts in systemic sclerosis? Ann Rheum Dis 2020;79:e55

2 Magalon J, Velier M, Simoncini S, et al. Molecular profile and proangiogenic activity of the adipose-derived stromal vascular fraction used as an autologous innovative medicinal product in patients with systemic sclerosis. Ann Rheum Dis 2019;78:391-8. 
3 Di Benedetto P, Cipriani P, Ruscitti P, et al. Adipose stromal vascular fraction and regenerative therapy in SSc: response to the article by Magalon et al. Ann Rheum Dis 2020;79:e53.

4 Magalon J, Velier M, Simoncini S, et al. Response to: 'Adipose stromal vascular fraction and regenerative therapy in SSc: response to the article by Magalon et al' by De Benedetto et al. Ann Rheum Dis 2020;79:e54.

5 Del Papa N, Caviggioli F, Sambataro D, et al. Autologous fat grafting in the treatment of fibrotic perioral changes in patients with systemic sclerosis. Cell Transplant 2015;24:63-72.

6 Sautereau N, Daumas A, Truillet R, et al. Efficacy of autologous Microfat graft on facial handicap in systemic sclerosis patients. Plast Reconstr Surg Glob Open 2016;4.

7 Del Papa N, Di Luca G, Sambataro D, et al. Regional implantation of autologous adipose tissue-derived cells induces a prompt healing of long-lasting indolent digital ulcers in patients with systemic sclerosis. Cell Transplant 2015;24:2297-305.

8 Benedetto PD, Liakouli V, Ruscitti P, et al. Blocking CD248 molecules in perivascular stromal cells of patients with systemic sclerosis strongly inhibits their differentiation toward myofibroblasts and proliferation: a new potential target for antifibrotic therapy. Arthritis Research 2018;20.
9 Virzì F, Bianca P, Giammona A, et al. Combined platelet-rich plasma and lipofilling treatment provides great Improvement in facial skin-induced lesion regeneration for scleroderma patients. Stem Cell Res Ther 2017;8:236.

10 Griffin M, Ryan CM, Pathan 0, et al. Characteristics of human adipose derived stem cells in scleroderma in comparison to sex and age matched normal controls: implications for regenerative medicine. Stem Cell Res Ther 2017:8:23

11 Capelli C, Zaccara E, Cipriani P, et al. Phenotypical and functional characteristics of in Vitro-Expanded adipose-derived mesenchymal stromal cells from patients with systematic sclerosis. Cell Transplant 2017;26:841-54.

12 Hirose Y, Funahashi Y, Matsukawa Y, et al. Comparison of trophic factors secreted from human adipose-derived stromal vascular fraction with those from adipose-derived stromal/stem cells in the same individuals. Cytotherapy 2018;20:589-91.

13 Granel B, Daumas A, Jouve E, et al. Safety, tolerability and potential efficacy of injection of autologous adipose-derived stromal vascular fraction in the fingers of patients with systemic sclerosis: an open-label phase I trial. Ann Rheum Dis 2015;74:2175-82. 